\title{
Mediastinal follicular dendritic cell sarcoma: a rare, potentially under-recognized, and often misdiagnosed disease
}

\author{
You-Li Wu, Feng Wu, Cheng-Ping Xu, Guo-Lei Chen, Yu Zhang, Wei Chen, Xiao-Chu Yan and Guang-Jie Duan * (D)
}

\begin{abstract}
Background: Mediastinal follicular dendritic cell sarcoma (FDCS) is extremely rare. Due to potential under-recognization of this disease, it happens to be misdiagnosed, especially on core needle biopsy. We report 3 cases of mediastinal FDCS and provide a literature review to improve better understanding of the tumor and to reduce misdiagnosis.

Methods: Three cases of mediastinal FDCS in our clinic practice were studied, including their core needle biopsy and resected specimens, and those cases reported previously in English literature were retrieved and analyzed.

Results: The core needle biopsy of case 1 showed a tumor reminiscent of classical Hodgkin's lymphoma (CHL), while the resected mass was finally diagnosed with FDCS combined with hyaline-vascular Castleman's disease. Both the biopsy and resected tissue of case 2 were constitutive of the clear epithelioid cells with marked atypia. In both cases, definitive diagnoses were not made on core needle biopsy. In case 3, there were some areas morphologically similar to CHL, and some areas contained ovoid to spindle-shaped tumor cells with fascicular pattern. The analysis of 43 cases of mediastinal FDCS showed the age of patients were from 16 to 76 years old, the male to female ratio was 1.5:1, the maximal tumor diameters were 3-17 cm. 18 cases were underwent preoperative biopsy, whereas 15 (83.3\%) of which were misdiagnosed initially, often as lymphoma. 32 patients had available follow-up data, the rates of recurrence, metastasis, and mortality were $12.5,18.8$ and $28.1 \%$, respectively. Current limited data suggested no statistical differences between adverse prognosis and gender, age, tumor size, necrosis, or different therapeutics, respectively.

Conclusions: Mediastinal FDCS is a rare malignancy that has yet not been fully understood and been often misdiagnosed, particularly when making a diagnosis on core needle biopsy. Increased awareness of this enigmatic tumor is crucial to avoid diagnostic pitfalls.
\end{abstract}

Keywords: Follicular dendritic cell sarcoma, Mediastinum, Radiology, Pathological diagnosis, Prognosis

\section{Background}

Follicular dendritic cell sarcoma (FDCS) is a rare malignancy that originates from follicular dendritic cells featuring antigen-presenting activities [1]. Although the tumor has been found in both lymph nodes and extranodal sites, it is very scarce in the mediastinum, with approximately 40 cases so far reported in the English literature [2-32]. The clinical manifestations, radiological and pathological features of the tumor remain to be concluded. Due to potential under-recognization of

\footnotetext{
*Correspondence: yxcwq@163.com; gjduan@163.com

Institute of Pathology and Southwest Cancer Center, Southwest Hospital,

Third Military Medical University (Army Medical University), Chongqing 400038, China
}

mediastinal FDCS in clinicians and pathologists, it happens to be misdiagnosed or missed, especially on core needle biopsy, which may lead to a completely different treatment plan.

In this study, we presented detailedly 3 cases of mediastinal FDCS in our clinic practice, including core needle biopsy and resected specimens. Interestingly, our examination revealed that the morphology of core needle biopsy of 2 subjects were highly similar to those of classical Hodgkin's lymphoma (CHL) and, therefore, had a high likelihood of misdiagnosis. Meanwhile, we reviewed 40 cases of mediastinal FDCS reported previously to explore their clinicopathological characteristics, and paid particular attention to the diagnostic difficulties and

(c) The Author(s). 2019 Open Access This article is distributed under the terms of the Creative Commons Attribution 4.0 International License (http://creativecommons.org/licenses/by/4.0/), which permits unrestricted use, distribution, and reproduction in any medium, provided you give appropriate credit to the original author(s) and the source, provide a link to the Creative Commons license, and indicate if changes were made. The Creative Commons Public Domain Dedication waiver (http://creativecommons.org/publicdomain/zero/1.0/) applies to the data made available in this article, unless otherwise stated. 
potential pitfalls in the preoperative biopsy. Furthermore, we analyzed, for the first time, the factors correlated to adverse prognosis of the tumor.

\section{Methods}

\section{Clinical samples}

We retrieved our pathological archives from 2006 to 2017 in 3 hospitals affiliated to the Third Military Medical University and Chongqing University Cancer Hospital, 3 cases of mediastinal FDCS were found. Case slides were reviewed again by 2 independent pathologists to confirm the diagnosis. Related clinical information was from the hospital medical records. Preoperative radiologic images were verified by radiologist in our hospital. Follow-up information was obtained by tracing the regular review of the patients.

\section{Histological examination}

The $10 \%$ neutral buffered formalin-fixed, paraffin-embedded tissue blocks were cut into 4- $\mu$ m-thick sections for hematoxylin and eosin (HE) staining and light microscopy.

\section{Immunohistochemistry}

The immunohistochemical detection was performed on the automatic immunohistochemical staining device (BenchMark ${ }^{\mathrm{XT}}$, Roche), and the antibodies were listed below in Table 1. The known positive sections were used for positive controls, and the phosphate buffer saline (PBS) buffer solution was used for negative control.

\section{EBV-encoded RNA (EBER) in situ hybridization (ISH)}

ISH for EBER was performed in 3 cases using a detection kit (Zhong Shan Golden Bridge, Beijing, China). The brown signal on the nuclei of the tumor cell was defined as a positive reaction. The tissue of nasopharyngeal carcinoma was used for positive control, and the reactive hyperplasia of the lymph node was used for negative control.

\section{Literature review}

Mediastinal FDCS cases reported in English literature (before December 31, 2017) were retrieved by using PubMed, the references of which were also studied, so as to ensure the completeness of cases obtained from the literature. The clinicopathological information of the patients, such as the age, gender, tumor size and necrosis, imaging alterations, diagnosis and treatment process, prognostic information etc., was also collected.

\section{Statistical analysis}

The Software Packages for Social Science 19.0 for Windows (SPSS, Inc. Chicago, IL, USA) was used for statistical analyses. Overall survival and disease-free survival
Table 1 Antibodies used for immunohistochemical staining and results

\begin{tabular}{|c|c|c|c|c|c|}
\hline \multirow[t]{2}{*}{ Antibody } & \multirow[t]{2}{*}{ Clone } & \multirow[t]{2}{*}{ Source } & \multicolumn{3}{|c|}{ Results/Case No. } \\
\hline & & & Case 1 & Case 2 & Case 3 \\
\hline CD21 & EP64 & ZSGB & + & + & + \\
\hline CD23 & EP75 & ZSGB & $+($ Focal) & $+($ Focal $)$ & + \\
\hline CD35 & EP197 & ZSGB & + & + & - \\
\hline CXCL-13 & None & ZSGB & + & + & - \\
\hline D2-40 & D2-40 & ZSGB & + & - & + \\
\hline CD3 & EP41 & ZSGB & - & - & - \\
\hline CD20 & EP7 & ZSGB & - & - & - \\
\hline CD30 & EP154 & ZSGB & + (scattered) & - & - \\
\hline CD15 & $M M A+B Y 87$ & ZSGB & - & / & - \\
\hline S-100 & $4 C 4.9$ & ZSGB & - & - & - \\
\hline PLAP & EP194 & ZSGB & / & + (Weak) & / \\
\hline SALL4 & $6 \mathrm{E} 3$ & ZSGB & / & - & / \\
\hline CK & AE1/AE3 & ZSGB & - & - & - \\
\hline P63 & UMAB4 & ZSGB & - & - & - \\
\hline SMA & $1 \mathrm{~A} 4$ & ZSGB & $+($ Focal $)$ & / & - \\
\hline Desmin & D33 & ZSGB & - & / & - \\
\hline ALK & OTI1H7 & ZSGB & - & / & / \\
\hline EBV-LMP-1 & CS1-4 & ZSGB & - & - & - \\
\hline Ki-67 & MIB1 & $\mathrm{ZSGB}$ & $10 \%$ & $30 \%$ & $15 \%$ \\
\hline
\end{tabular}

PLAP, placental alkaline phosphatase; $C K$, Cytokeratin; SMA, smooth muscle actin; $A L K$, Anaplastic lymphoma kinase; EBV-LMP-1, Epstein-Barr virus latent membrane protein-1; +, positive; -, negative; /, None; ZSGB, Zhong Shan Golden Bridge, Beijing

rates were analyzed by Kaplan-Meier method. The correlation of the clinicopathological parameters with the adverse outcome (i.e. local recurrence, distant metastasis or death) were analyzed using the log-rank test. $P$ value less than 0.05 was considered statistical significance.

\section{Results}

\section{General information}

The information of 3 patients with mediastinal FDCS in ours is summarized in Table 2. Cough and expectoration were the main manifestations of case 1 and 2, whereas chest tightness and chest pain were presented in case 3 . No fever, fatigue, loss of appetite, or weight loss was observed in all cases.

\section{Radiology}

Computed tomography (CT) images of case 1 showed that in the right upper anterior mediastinum adjacent to trachea, there was a mass of $5.0 \times 4.9 \times 4.7 \mathrm{~cm}$, which had relatively distinct border and adhered tightly to the mediastinal vessels. After enhanced scan, the lesion had obviously heterogeneous enhancement (Fig. 1a, b). CT images of case 2 revealed that in the right posterior mediastinum, there was a giant lobulated shadow 
Table 2 Summaries of 43 cases of mediastinal follicular dendritic cell sarcomas

\begin{tabular}{|c|c|c|c|c|c|c|c|c|}
\hline Case No. & Age/sex & $\begin{array}{l}\text { Tumour size } \\
(\max )\end{array}$ & Necrosis & Initial diagnosis & Treatment & $\begin{array}{l}\text { Recurrence/ } \\
\text { Metastasis (mo) }\end{array}$ & Status & $\begin{array}{l}\text { Follow-up } \\
\text { (mo) }\end{array}$ \\
\hline $1[3]$ & $62 / M$ & NA & Widespread & FDCS & Surg+ChT & Metastasis (24mo) & STD & 24 \\
\hline 2 [3] & $46 / \mathrm{M}$ & NA & Widespread & FDCS & Surg+RT & No & NED & 12 \\
\hline $3[3]$ & $31 / \mathrm{M}$ & NA & No & FDCS & Surg & No & NED & 10 \\
\hline $4[4]$ & $44 / F$ & $3 \mathrm{~cm}$ & No & FDCS & ChT & NA & NA & NA \\
\hline $5[5]$ & $43 / \mathrm{M}$ & $4 \mathrm{~cm}$ & No & $\begin{array}{l}\text { Peripheral nerve } \\
\text { sheath tumor }\end{array}$ & Surg & recurrences (36mo) & AWD & 36 \\
\hline $6[6]$ & $42 / \mathrm{M}$ & NA & NA & FDCS & Surg & No & NED & NA \\
\hline 7 [7] & $35 / M$ & $4 \mathrm{~cm}$ & Yes & FDCS & $\mathrm{RT}+\mathrm{ChT}$ & No & STD & 7 \\
\hline 8 [8] & $76 / \mathrm{M}$ & $10 \mathrm{~cm}$ & Yes & FDCS & Surg & No & NED & 24 \\
\hline 9 [9] & $45 / M$ & $15 \mathrm{~cm}$ & No & $\begin{array}{l}\text { Diffuse large B-cell } \\
\text { lymphoma/Tuberculosis }\end{array}$ & Surg+ChT & $\begin{array}{l}\text { multiple recurrences } \\
\text { (156mo) }\end{array}$ & AWD & 204 \\
\hline 10 [10] & $46 / F$ & $8.4 \mathrm{~cm}$ & No & $\begin{array}{l}\text { Diffuse large B-cell } \\
\text { lymphoma }\end{array}$ & $\mathrm{RT}+\mathrm{ChT}$ & Metastasis (12mo) & AWD & 24 \\
\hline $11[11]$ & $43 / M$ & $13 \mathrm{~cm}$ & NA & FDCS & Surg & NA & NA & NA \\
\hline 12 [12] & $45 / F$ & $8.4 \mathrm{~cm}$ & NA & $\begin{array}{l}\text { Diffuse large B-cell } \\
\text { lymphoma }\end{array}$ & ChT & No & AWD & 22 \\
\hline 13 [12] & $41 / F$ & $5 \mathrm{~cm}$ & NA & FDCS & Surg+RT + ChT & No & NED & 107 \\
\hline 14 [13] & $60 / \mathrm{M}$ & $6 \mathrm{~cm}$ & NA & FDCS & Surg+ChT & No & STD & 6 \\
\hline 15 [14] & $49 / F$ & $9 \mathrm{~cm}$ & NA & FDCS & Surg & No & NED & 28 \\
\hline $16[15]$ & $39 / M$ & $8 \mathrm{~cm}$ & NA & FDCS & Surg & NA & NA & NA \\
\hline $17[16]$ & 23/M & $8 \mathrm{~cm}$ & Focal & $\begin{array}{l}\text { Malignant nerve } \\
\text { sheath tumor }\end{array}$ & Surg+RT + ChT & Metastasis (45mo) & AWD & 45 \\
\hline 18 [17] & $72 / F$ & NA & NA & FDCS & Surg & No & NED & 8 \\
\hline 19 [18] & $47 / M$ & $7.5 \mathrm{~cm}$ & NA & FDCS & RT & No & AWD & 14 \\
\hline 20 [19] & $52 / F$ & NA & Yes & FDCS & Surg & NA & NA & NA \\
\hline $21[20]$ & $42 / M$ & $6 \mathrm{~cm}$ & NA & Malignancy & Surg+RT & No & NED & 20 \\
\hline $22[21]$ & $68 / \mathrm{M}$ & $4.5 \mathrm{~cm}$ & No & FDCS & Surg & No & NED & 24 \\
\hline $23[22]$ & $63 / M$ & $13.4 \mathrm{~cm}$ & Widespread & $\begin{array}{l}\text { Malignant neoplasm } \\
\text { (thymic epithelial } \\
\text { origin) }\end{array}$ & Surg & NA & NA & NA \\
\hline 24 [23] & $37 / M$ & $11 \mathrm{~cm}$ & Yes & $\begin{array}{l}\text { necrotic material } \\
\text { with no well-defined } \\
\text { granulomas }\end{array}$ & Surg+RT + ChT & No & NED & 6 \\
\hline $25[24]$ & $62 / \mathrm{M}$ & $7.5 \mathrm{~cm}$ & NA & $\begin{array}{l}\text { No atypical cells } \\
\text { were obtained }\end{array}$ & Surg+RT & No & STD & 7 \\
\hline $26[25]$ & $34 / \mathrm{M}$ & NA & NA & $\begin{array}{l}\text { Low-grade non- } \\
\text { Hodgkin lymphoma }\end{array}$ & Surg+RT + ChT & $\begin{array}{l}\text { multiple recurrences } \\
\text { (131mo) }\end{array}$ & AWD & 312 \\
\hline 27 [26] & 39/M & $6 \mathrm{~cm}$ & NA & FDCS & Surg+RT & No & NED & 96 \\
\hline $28[27]$ & $72 / F$ & $4.3 \mathrm{~cm}$ & NA & FDCS & RT & Metastasis (12mo) & STD & 12 \\
\hline $29[27]$ & $51 / F$ & $9.1 \mathrm{~cm}$ & NA & FDCS & Surg+RT & Metastasis (10mo) & STD & 10 \\
\hline 30 [27] & $53 / F$ & $10.3 \mathrm{~cm}$ & NA & FDCS & Surg & No & NED & 18 \\
\hline $31[28]$ & 29/M & $10 \mathrm{~cm}$ & No & NA & Surg+ChT & $\begin{array}{l}\text { multiple recurrences } \\
(48 \mathrm{mo})\end{array}$ & AWD & 102 \\
\hline $32[28]$ & $25 / M$ & $13.5 \mathrm{~cm}$ & Widespread & NA & Surg+RT + ChT & No & NED & 13 \\
\hline 33 [28] & $20 / F$ & $11.5 \mathrm{~cm}$ & No & NA & Surg & NA & NA & NA \\
\hline 34 [28] & $61 / \mathrm{M}$ & $14 \mathrm{~cm}$ & No & NA & Surg+RT + ChT & No & STD & 57 \\
\hline 35 [28] & $40 / F$ & $4.2 \mathrm{~cm}$ & No & NA & Surg & NA & NA & NA \\
\hline $36[28]$ & $23 / \mathrm{M}$ & $6.3 \mathrm{~cm}$ & Focal & NA & Surg & No & NED & NA \\
\hline
\end{tabular}


Table 2 Summaries of 43 cases of mediastinal follicular dendritic cell sarcomas (Continued)

\begin{tabular}{|c|c|c|c|c|c|c|c|c|}
\hline Case No. & Age/sex & $\begin{array}{l}\text { Tumour size } \\
\text { (max) }\end{array}$ & Necrosis & Initial diagnosis & Treatment & $\begin{array}{l}\text { Recurrence/ } \\
\text { Metastasis (mo) }\end{array}$ & Status & $\begin{array}{l}\text { Follow-up } \\
\text { (mo) }\end{array}$ \\
\hline 37 [29] & $16 / F$ & $8 \mathrm{~cm}$ & No & FDCS & Surg & No & NED & 24 \\
\hline 38 [30] & $46 / F$ & $11 \mathrm{~cm}$ & NA & $\begin{array}{l}\text { Mediastinitis/Hodgkin } \\
\text { lymphoma }\end{array}$ & Surg+RT + ChT & Metastasis (25mo) & STD & 28 \\
\hline 39 [31] & $27 / F$ & $17 \mathrm{~cm}$ & NA & Suspicion of malignancy & ChT & No & STD & 6 \\
\hline $40[32]$ & $71 / F$ & $5.9 \mathrm{~cm}$ & NA & NA & Surg+RT & No & NED & 15 \\
\hline 41 & $52 / F$ & $5 \mathrm{~cm}$ & Focal & $\begin{array}{l}\text { Suspicion of Hodgkin } \\
\text { lymphoma }\end{array}$ & Surg+ChT & No & NED & 60 \\
\hline 42 & $46 / M$ & $13 \mathrm{~cm}$ & Widespread & Malignant neoplasm & Surg & NA & NA & NA \\
\hline 43 & $65 / M$ & $9.5 \mathrm{~cm}$ & No & FDCS & NA & NA & NA & NA \\
\hline
\end{tabular}

41-43 Present cases; NA, not available; FDCS, follicular dendritic cell sarcoma; Surg, surgery; RT, radiotherapy; ChT, chemotherapy; NED, no evidence of disease; $A W D$, alive with disease; STD, succumbed to disease
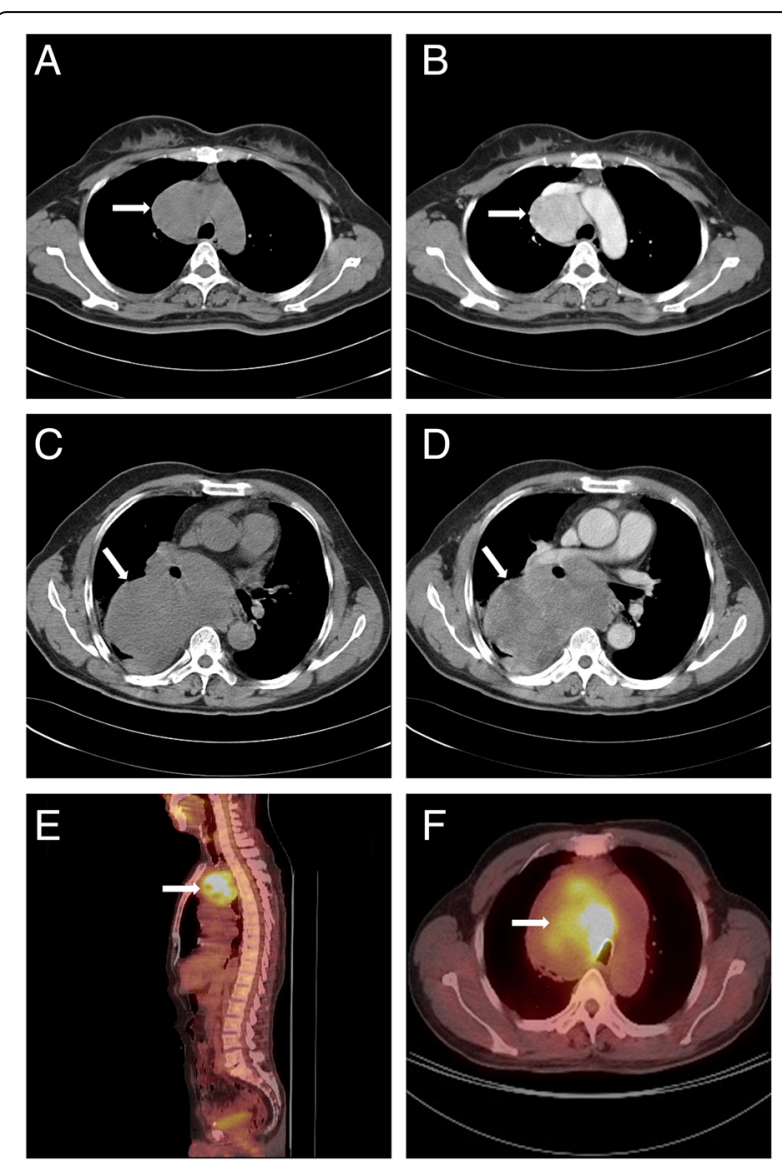

Fig. 1 Axial CT of case 1 shows a mass with distinct border in the right upper anterior mediastinum (a), which presents an obviously heterogeneous enrichment after enhancement (b). Axial plain (c) and enhanced (d) CT of case 2 reveal that in the right posterior mediastinum, there is a giant lobulated shadow with moderately heterogeneous enhancement. Sagittal (e) and axial (f) positron emission tomography and $C$ of case 3 indicate a mass in the middle mediastinum with avid fluorodeoxyglucose uptake (SUVmax = 11.95) measured $13.0 \times 12.6 \times 7.6 \mathrm{~cm}$. Post-contrast CT scaning displayed moderately heterogeneous enhancement of the lesion. The boundaries between the lesion and right pulmonary artery, esophagus and right bronchus were not clear (Fig. 1c, d). CT images of case 3 showed a mass in the middle mediastinum, $9.5 \times 9.2 \times 8.8 \mathrm{~cm}$ in size, which had clear boundary. The adjacent tracheae was slightly stenotic due to tumor compression. Positron emission tomography and CT (PET-CT) revealed significantly increased fluorodeoxyglucose $\left({ }^{18} \mathrm{~F}-\mathrm{FDG}\right)$ uptake (SUVmax =11.95), with most being internal uptake (Fig. 1e, f).

\section{Morphology and immunophenotype of the tumors}

Microscopic examination of the core needle biopsy of case 1 showed a few large round or ovoid cells scattered in the inflammatory background composed of lymphocytes, plasma cells and histocytes. These cells had delicate chromatin and large nuclei with distinct nucleoli, and were reminiscent of Hodgkin and Reed-Sternberg (HRS) cells (Fig. 2a, b, arrows). Immunohistochemical staining showed that these large cells were negative for cytokeratin (CK), P63, CD3, CD20, but a few were CD30 positive. Thus, the tumor was suspected to be classical Hodgkin lymphoma (CHL). However, the patient suffered haemorrhage during the puncture, which prompted emergency resection of the mediastinal mass. The resulting specimen was a grey mass with clear boundary and partial capsule. Microscopic examination showed the following findings: the main element of the tumor was composed of ovoid and spindle-shaped cells with fascicular, woven or storiform patterns, in the background, there were infiltrations of varying levels of lymphocytes, plasma cells, and eosinophils; some areas exhibited classical morphology of hyaline-vascular Castleman's disease (HVCD). Between hyperplastic follicular dendritic cells in HVCD areas and surrounding spindle-shaped cells, there were transitional zones (Fig. 2c, d). Multinucleated giant cells and HRS-like cells were disseminated in HVCD areas, hyperplastic 

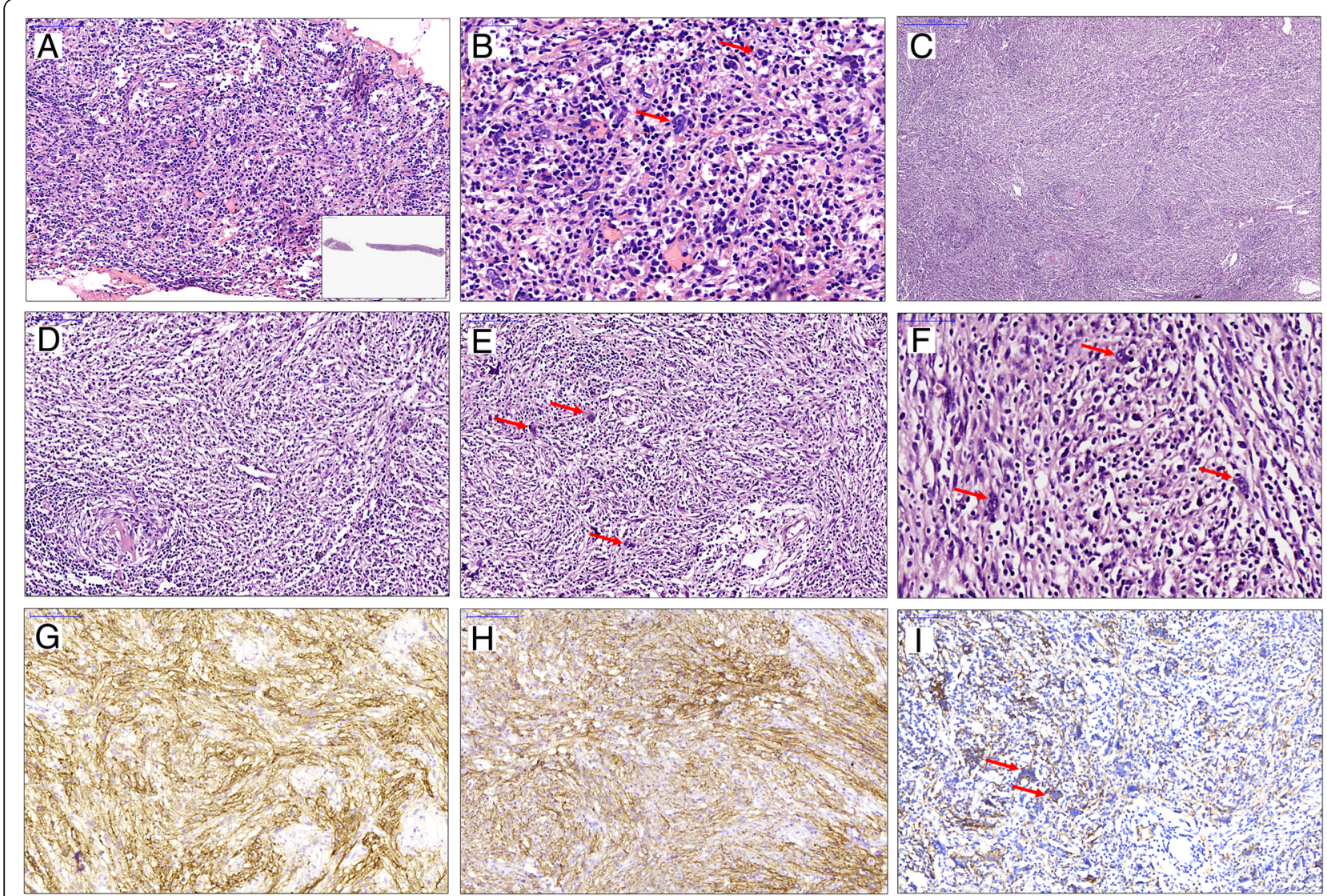

Fig. 2 Case 1: HE staining of core needle biopsy specimen shows there are a few large round or ovoid cells scattered in the inflammatory background (a, inset: low-power view of needle biopsy), which are reminiscent of Hodgkin and Reed-Sternberg cells (b, arrows). Microscopic examination of resected specimens exhibit the classical morphology of hyaline-vascular Castleman's disease (c, lower left area) and hyperplastic ovoid to spindle cells (c, upper right area). High-power view of figure $\mathrm{C}$ shows the transitional zones (d). Multinucleated giant cells and Hodgkin and Reed-Sternberg-like cells are disseminated in the lesions (e, $\mathbf{f}$, arrows). Immunohistochemical staining shows the spindle cells (including some scattered large cells) are positive for CD21 (g), CD35 (h) and D2-40 (i, arrows)

lesions of spindle-shaped cells, and the transitional zone in-between (Fig. 2e, f, arrows). Immunohistochemical staining showed that spindle-shaped cells (including some scattered large cells) expressed CD21 (Fig. 2g), CD23, CD35 (Fig. 2h), D2-40 (Fig. 2i, arrows), CXCL-13 and SMA at various degrees, a few large cells were CD30-positive, and the ki-67 labeling index was $10 \%$. All of these cells were negative for CK, P63, Desmin, ALK, S-100 and EBV-LMP-1. Based on these results, the patient was diagnosed with FDCS combined with HVCD.

In case 2, microscopically, the needle biopsy specimens revealed that the tumor cells were round or ovoid with light red or clear cytoplasm, large and hyperchromatic nuclei, which were arranged into nests. Between these tumor nests, fibrosis and varying levels of lymphocytes infiltration were observed (Fig. 3a, b). Immunohistochemical staining showed that the tumor cells were negative for CK, P63, CD3, CD20, CD30, S-100, and weak positive for placental alkaline phosphatase (PLAP).
So, a malignant tumor without further classification was made. During the surgery, the tumor was found to locate in the right posterior mediastinum and to have invaded into the right lung and oesophageal external wall. The resected specimen was a grey to white lobulated mass with clear boundary but no capsule. The tumor was tightly connected to partial pulmonary tissues; the cross-section was grey to brown with moderate texture, and contained bleeding and necrosis. Microscopic examination revealed that round to ovoid epithelioid tumor cells with marked atypia were tightly arranged into nested or a diffuse pattern. There were multifocal coagulative necrosis and a few dispersed lymphocytes in the background. The surrounding pulmonary tissue was invaded by tumor cells (Fig. 3c-e). Immunohistochemical analysis revealed that the tumor cells were positive for CD21 (Fig. 3f), CD35 and CXCL-13, focal positive for CD23, while negative for D2-40, CK, P63, CD30, SALL4, PLAP, EBV-LMP-1. The ki-67 labeling index was $30 \%$. Thus the posterior mediastinal FDCS with right lung involvement was diagnosed. 

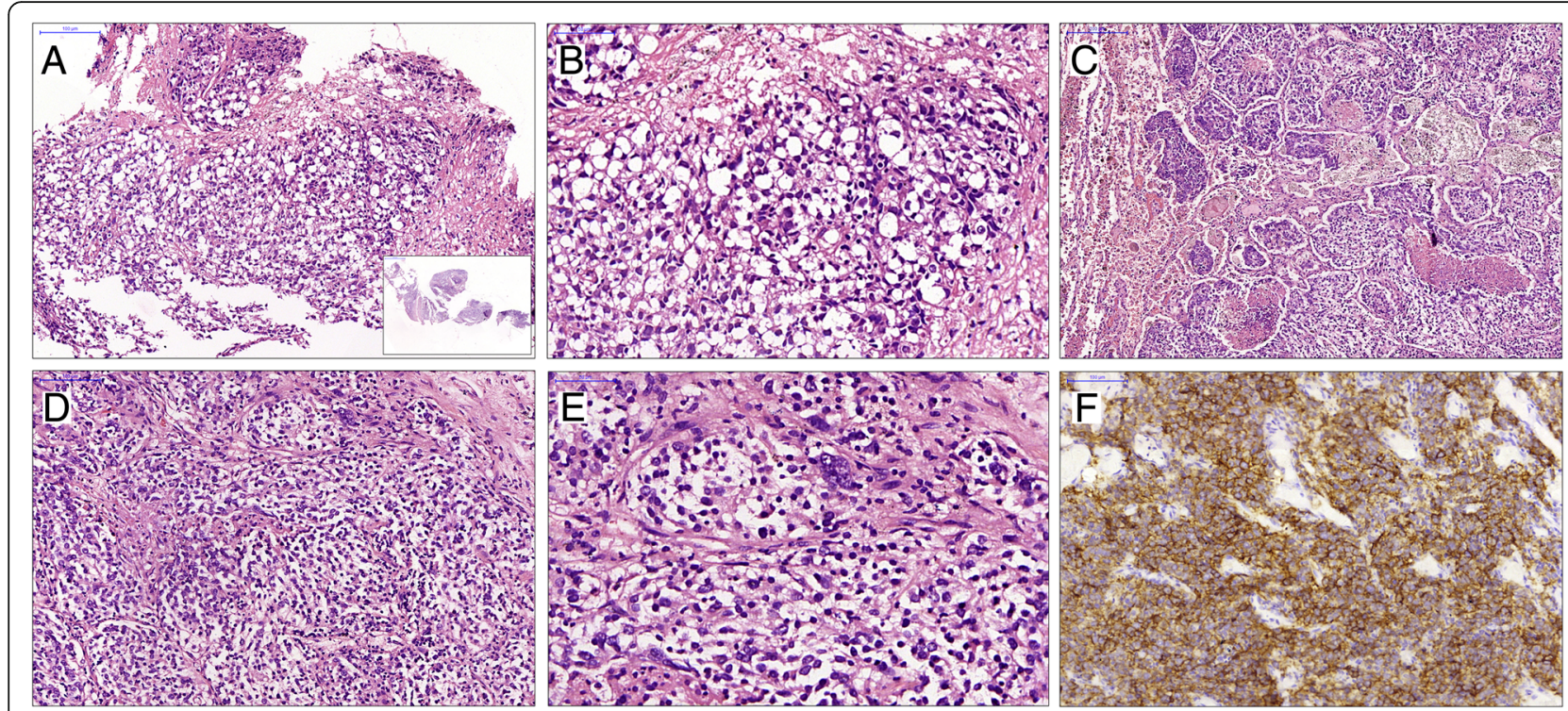

Fig. 3 Case 2: HE staining of needle biopsy specimen reveals that round or ovoid tumor cells with clear cytoplasm are arranged into nests (a, inset: low-power view of needle biopsy), and high-power view shows the epithelioid cells with moderate to marked cytological atypia (b). Resected specimens reveal that epithelioid tumor cells with sheet or nest-like distribution invade into the pulmonary tissues (c, left area), and multifocal coagulative necroses are seen (c), moderate and high-power view of which show the clear epithelioid tumor cells (d, e) with CD21 expression (f), similarly to those of core needle biopsy

In core needle biopsy of case 3, two different histopathological morphology was identified, with some areas resembling that of case 1 , specifically, in the inflammatory background composed of with lymphocytes, plasma cells and histocytes, there were scattered large round or ovoid cells resembling lacunar Reed-Sternberg (LHS) cells (Fig. 4a, b, arrows). In other areas, there were ovoid and spindle-shaped tumor cells with bundles and woven patterns, the tumor cells had abundant and slightly eosinophilic cytoplasm, and hyperchromatic nuclei (Fig. 4d, e). Immunohistochemical staining showed that tumor cells in both areas were positive for CD21, CD23 (Fig. 4c, f) and D2-40, while negative for CD35, CXCL-13, CK, P63, CD30, S-100, EBV-LMP-1. The ki-67

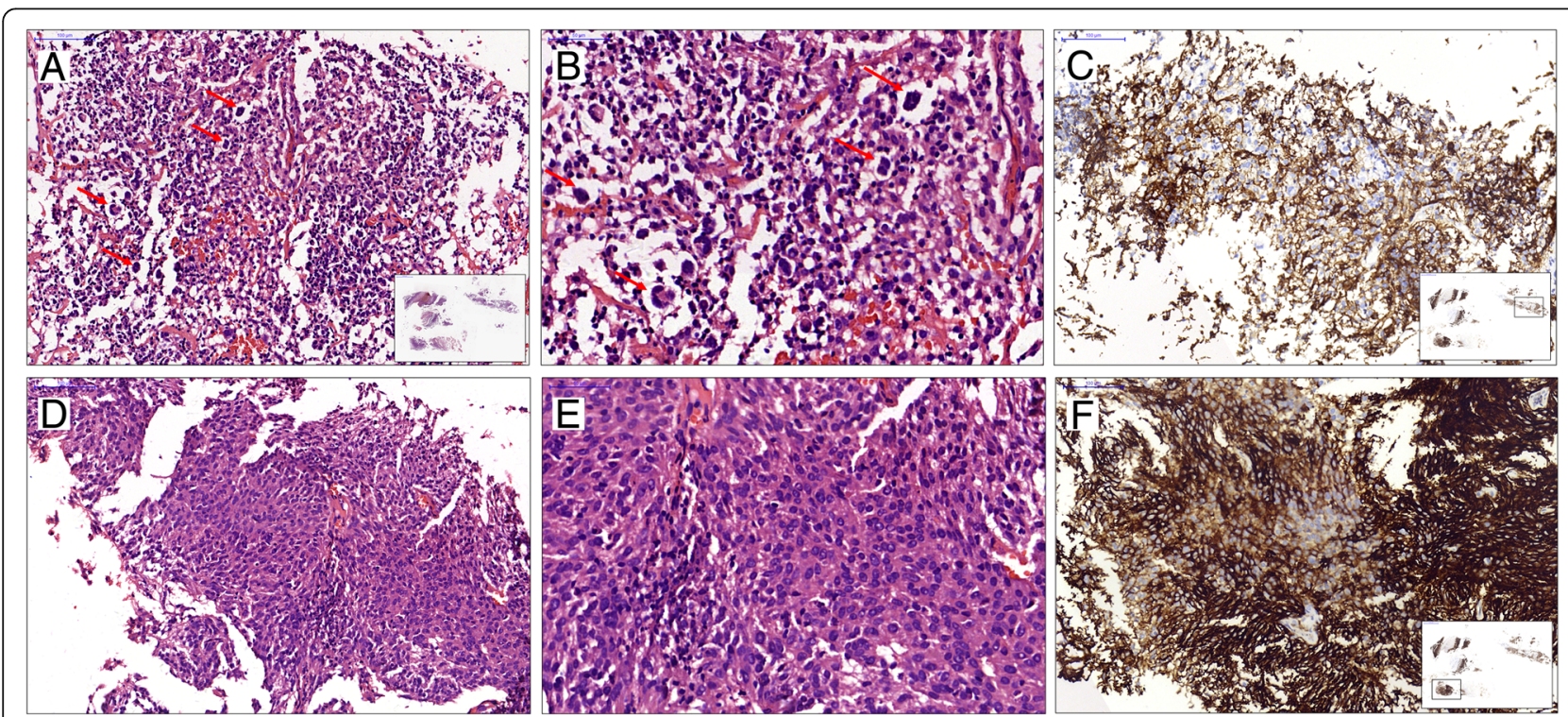

Fig. 4 Case 3: HE staining of core needle biopsy specimen shows 2 different histopathological morphologies: one is that in the inflammatory background, there are scattered large round or ovoid cells resembling lacunar Reed-Sternberg cells (a, b, arrows, inset: low-power view of needle biopsy), another presents ovoid and spindle tumor cells with bundles and woven patterns (d, e), both of which are positive for CD23 (c, f, inset: low-power view of immunohistochemical staining of needle biopsy) 
labeling index was $15 \%$. The patient was diagnosed with FDCS.

\section{Results of ISH}

The tumor cells were all negative for EBER by ISH in 3 cases.

\section{Literature review}

Literature retrieved 40 cases of mediastinal FDCS (Table 2), plus with 3 cases in ours, generated a total of 43 cases for statistical analysis, including 26 males and 17 females. The ages arrange was from 16 to 76 years old (mean age 46 years, and median age 45 years). The maximal tumor diameters were $3-17 \mathrm{~cm}$ (mean $8.6 \mathrm{~cm}$ and median $8.2 \mathrm{~cm}$ ). Of 24 cases, concurrent necrosis was found in 12 cases (including 5 cases with extensive necrosis), but another 19 subjects had no relevant records.

Among the 43 cases, 18 underwent preoperative needled biopsy, 15 of which (83.3\%) were misdiagnosed initially. Mediastinal FDCS was often diagnosed as other types of tumor or non-tumor lesions, including lymphoma (7 cases), malignant tumor (without classification, 3 cases), malignant schwannoma (2 cases), undifferentiated carcinoma ( 2 cases), thymoma ( 1 case), germ cell tumors (1 case), or no atypical cells ( 2 cases).

Available follow-up data was obtained from 32 subjects, the follow-up duration was 6-312 months, averaging 43 months. The rates of recurrence, metastasis, and mortality were $12.5,18.8$ and $28.1 \%$, respectively. The 1-, 3-, and 5-year total survival rates were 80.4, 68.5 , and 58.8\%, respectively, and the 1-, 3-, and 5-year tumor-free total survival rates were $76.9,51.7$, and $32.3 \%$, respectively (Fig. 5a, b).

\section{Prognosis associated factors}

Given the limitations in sample numbers and availability of clinical data (reliable data were not easy to obtain for mitotic figures and nuclear pleomorphism), we only analyzed the associations of poor prognosis with the following clinical factors: gender, age, maximal tumor diameter, and presence of necrosis. Our analysis revealed that there were no significant differences in either total survival rate or tumor-free survival rate within sex, age, tumor size and necrosis subgroups (Fig. 6a-h). Next, we compared prognosis differences between different treatments (8 underwent surgery only vs 18 underwent surgery plus adjuvant radiotherapy/chemotherapy), and there was no differences in either total survival rate or tumor-free survival rate (Fig. 6i-j).

\section{Discussion}

Mediastinal FDCS is a rare disease. Currently, there is a lack of systematic, large-sample studies on its clinical manifestations, radio-pathological links, and prognosiscorrelated factors. In this study, we analyzed a large group of mediastinal FDCS (43 cases), including patients admitted in our hospital and those from the literature [3-32]. The subjects were an average of 46 years old, and sex ratio was 1.5:1 (M:F). The clinical manifestations were not specific, but closely associated with the site of tumor occurrence. A few patients were occasionally found lesions during physical examination. Interestingly, 4 cases had paraneoplastic pemphigus (PNP) as the first clinical manifestation $[9,13,24,26]$, whereas 3 cases had myasthenia gravis (MG) as the main symptom [5, 15, 17]. Because MG is common in patients with thymoma, preoperative diagnosis is expected to be a challenge for these cases.

Among the 43 cases, 19 cases published with radiological image data, which indicated that the tumors often presented a round or lobulated shadow with clear border. After enhanced scan, the tumor showed obviously enhancement. The tumors were commonly relatively large in size. Calcification was found in $52.6 \%$ of
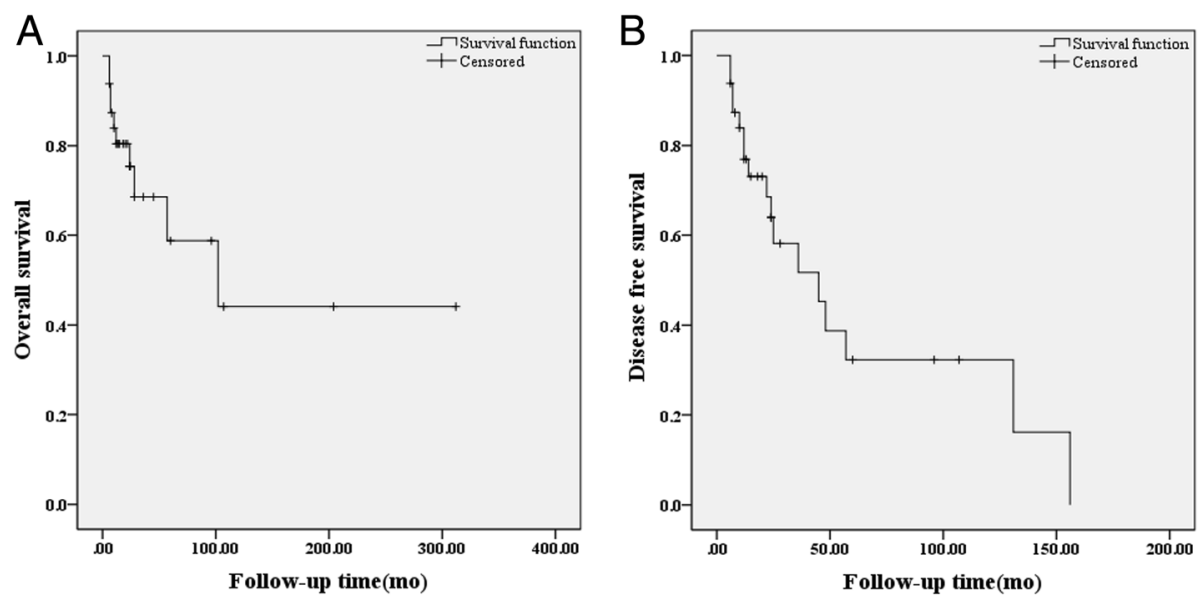

Fig. 5 Survival curves of mediastinal FDCS, overall survival (a) and disease-free survival (b) 


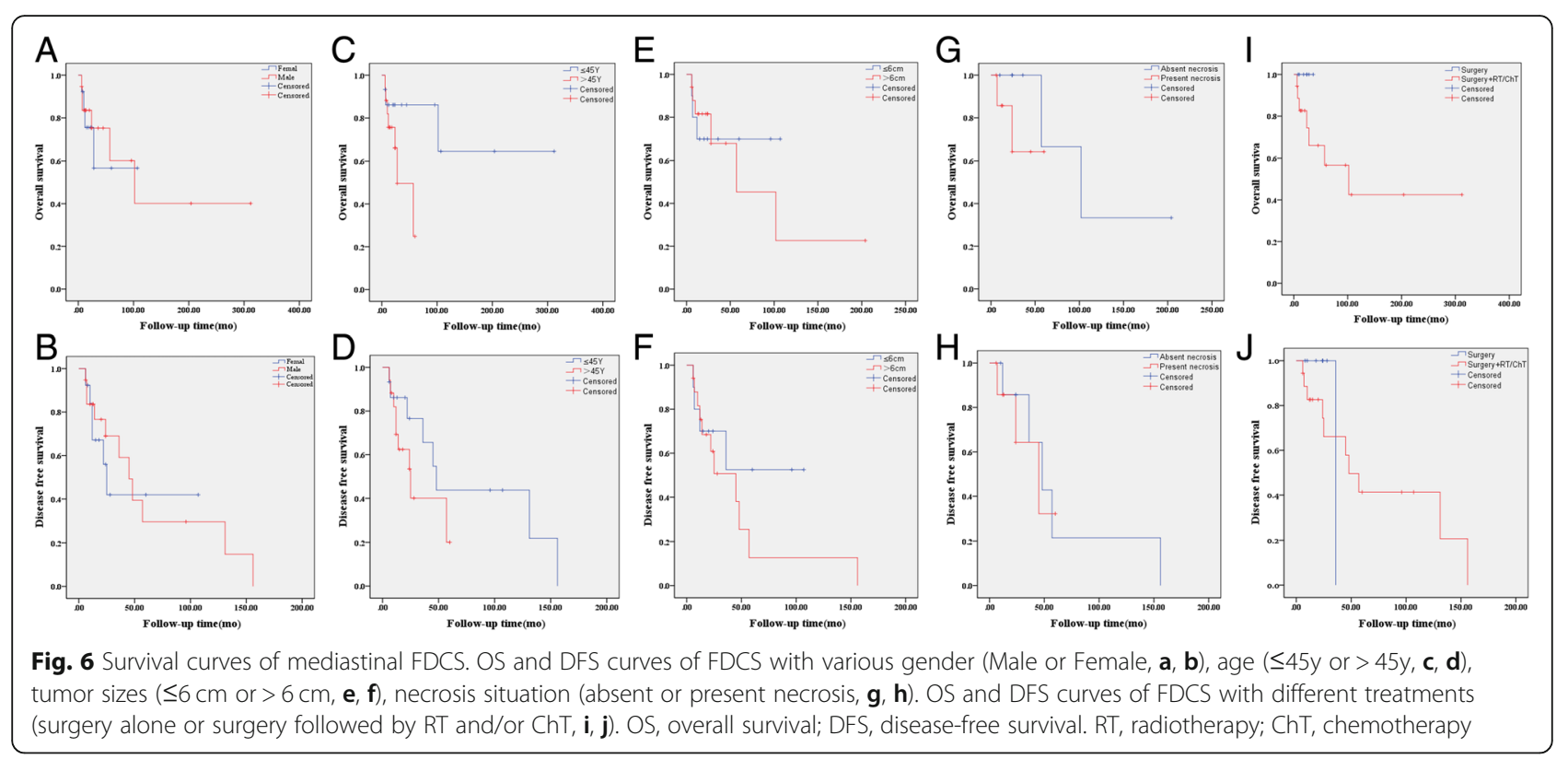

the cases, although bleeding and necrosis were rare. It was proposed that if a mediastinal mass had clear border, calcification, but rare bleeding and necrosis, the condition was highly likely FDCS [11, 27]. Some cases may develop HVCD-like imaging alterations. For example, Case 1 in ours had concurrent HVCD and displayed obvious enhancement, which was highly similar to HVCD and practically indistinguishable from it in CT images [21]. Of note, Case 1 suffered haemorrhage during preoperative puncture, which also occurred for one of the cases in the literature [18]. Above-mentioned cases remind us if the tumor image displays apparent intensification after enhance scan, which indicates it may be rich blood supply and vulnerable to haemorrhage, the puncture risk assessment is necessary. There are very few reports on the PET-CT features of mediastinal FDCS (only 4 cases), with SUVmax values ranging from 2.7 to 11.4. The SUVmax of Case 3 was 11.95 , indicating that the tumor had a relatively high metabolic level.

Most cases with mediastinal FDCS manifest the typical morphology of conventional FDCS. However, some cases may develop marked atypia or epithelioid or CHL-like features, which present a great challenge to diagnosis, particularly preoperative needle-based diagnosis. Of the 43 cases analyzed in this study, 18 received core needle biopsy but had an overall misdiagnosis rate of $83.3 \%$, illustrating the extraordinary difficulty involved in identifying the disease. Core needle biopsy is of vital importance to mediastinal tumors, in particular for those that are difficult to remove surgically, because their subsequent therapeutics almost rely on the preoperative examination. Based on our diagnostic experience and literature, the causes of diagnostic difficulty may be attributed to the following: (1) mediastinal FDCS lacks unique clinical signs and may present unusual symptoms such as PNP or MG; (2) although radiologic image is indicative to a certain extent, its diagnostic value is limited; (3) the tumors are heterogeneous, often with concurrent inflammation and fibrosis, thus small needle specimen can not fully represent the whole tumor; and (4) mediastinal FDCS is so scarce that clinicians and pathologists often do not considered it during diagnosis. Hence, increased awareness of this rare mediastinal tumor and consideration of detection of the FDC-associated markers are crucial to avoid pitfalls.

An important scenario that should raise a red flag is that, based on the data from the literature and our experience, mediastinal FDCS is the most likely to be diagnosed as lymphoma (7/18 cases). Two of the biopsy specimens obtained in our hospitals also displayed a CHL-like appearance; specifically, such morphology refers to the scattered Reed-Sternberg-like large cells and multinucleated giant cells, which may express CD30, in a mixed inflammatory background. This critical issue can potentially be a diagnostic trap because once a patient is diagnosed as $\mathrm{CHL}$, he/she likely receives unsuitable treatments. As for the differential diagnosis between the two entities, there are several points to note. (1) Reed-Sternberg-like large cells and CD30 positivity are very limited role, because these scattered large cells are often found in FDCS in different locations [2, 33, 34], and part of which could expression CD30 [35]. (2) It is the most important that when such 
lesion is presented in a needle biopsy of mediastinal mass, it should be considered not only the possibility of CHL but also that of FDCS. (3) The markers correlated to FDCS and CHL should be detected, including EBER ISH. If the large cells are positive for CD30, CD15, Mum-1, GATA3, PAX5 (weak positive) and EBER, but FDC-associated markers are negative, $\mathrm{CHL}$ is considered. On the contrary, if only CD30 and FDC-associated markers are positive, it should be considered as FDCS.

Previously, it was considered that adverse outcome of FDCS could be attributed to the following aspects: its intra-abdominal location, its large size (often $>6 \mathrm{~cm}$ in diameter), the presence of coagulative necrosis, the high proportion of mitotic figures (>5/10 HPF), and the marked nuclear atypia. However, whether these factors are suitable for mediastinal FDCS is unclear. Current limited data suggested that none of the factors (gender, age, tumor size, and presence of necrosis) were correlated with the adverse outcome. Of course, an accumulated large sample size and long follow-up duration are needed to better investigate this issue.

Currently, there is a lack of consensus on treatment of FDCS, but radical resection is the predominant option, and adjuvant radiochemotherapy remains controversial $[1,25,36]$. In this study, a comparison of prognosis between the surgery only group and the surgery plus adjuvant therapy group found no differences in either total or tumor-free survival. However, it is note that the cases available for analysis are scarce, and the survival curves based on a compliation of small series and case reports, so the aboved results may be insufficiently valid. Thus, further studies are needed to better explore the effects of adjuvant therapy.

The aetiology of FDCS remains elusive. It has been reported that its occurrence is closely related to HVCD, which, rather than a reactive alteration in tumor stroma, is more likely a type of precancer lesion [28, 37]. Chan et al. reported a clinical case in which HVCD evolved into FDCS [38]. Of the 43 cases of mediastinal FDCS, 8 (18.6\%) had concurrent HVCD. For example, case 1 had a transitional zone between the HVCD and the FDCS, corroborating that they might correspond to different phases of the same disease. Hence, when examining a patient with a putative mediastinal HVCD, it is important to maximize the sample areas and to perform a thorough microscopic examination, thereby avoiding potential FDCS lesions being missed. Epstein-Barr virus (EBV) infection is considered to be closely linked to the occurrence of inflammatory pseudotumor-like FDCS, but conventional FDCS seldom have concurrent EBV infection [33, 39]. Of the 43 cases, 10 were detected by EBER ISH, which were all negative.

Little is known about the pathogenesis of FDCS, only a few studies have been reported so far [35]. Go et al. performed BRAF sequencing and identified V600E mutations in 5 of 27 FDCS cases (18.5\%) [40]. In our 3 cases, BRAF mutation analysis was also performed by fluorescent PCR, but no V600E mutation was detected (data not shown). Recurrent loss-of-function alterations were revealed in tumor suppressor genes involved in the negative regulation of NF-kB (38\%) and cell cycle (31\%) through targeted sequencing [41]. Based on microRNA (miRNA) profiling of 31 FDCSs, Hartmann et al. identified two subgroups with high and low miRNA expression levels, which related to fibroblasts and myopericytomas or Castleman's disease, respectively [42]. Two newly researches on the whole transcriptome have shed new light on the pathobiology of FDCS. Laginestra et al. demonstrated FDCS has a distinct FDC-related transcriptional profile which allows differentiation from other mesenchymal tumors. The results also provide evidence of a peculiar immune microenvironment associated with FDCS that may have clinical utility [43]. By whole transcriptome sequencing, Lorenzi et al. identified two novel FDC markers, the FDC secreted protein and serglycin, and proposed an efficient marker panel for the diagnosis of this enigmatic tumor [32].

\section{Conclusions}

Mediastinal FDCS is very rare and lacks distinct clinical manifestations, which is a great challenge for diagnosis, especially on core needle biopsy. Mediastinal FDCS is the most likely to be diagnosed as lymphoma, which the differential diagnoses should be mostly focused on. Better understanding of this enigmatic tumor is important for augmenting its diagnostic accuracy.

\section{Abbreviations \\ ALK: Anaplastic lymphoma kinase; CHL: Classical Hodgkin's lymphoma; \\ CK: Cytokeratin; CT: Computed tomography; EBER: Epstein-Barr virus-encoded RNA; EBV: Epstein-Barr virus; EBV-LMP-1: Epstein-Barr virus latent membrane protein-1; EMA: Epithelial membrane antigen; FDCS: Follicular dendritic cell sarcoma; HVCD: Hyaline-vascular Castleman's disease; IHC: Immunohistochemistry; ISH: In situ hybridization; MG: Myasthenia gravis; PET-CT: Positron emission tomography and CT; PLAP: Placental alkaline phosphatase; PNP: Paraneoplastic pemphigus; RNA: Ribonucleic acid; SMA: Smooth muscle actin}

\section{Acknowledgments \\ The authors thank the patient for agreeing to our report and for providing a detailed medical history. They also thank the American Journal Experts who provided the professional language editing service. They are grateful to Qihui Jim Zhai, M.D., Department of pathology and laboratory medicine, Mayo Clinic, USA, for careful review and comment on the format and language of the manuscript.}

\section{Funding}

This work was financially supported by a grant from the Natural Science Foundation of China (No.81171848).

Availability of data and materials

The datasets used and/or analyzed during this study are available from the corresponding author on reasonable request. 


\section{Authors' contributions}

Study concepts and design: GJD, XCY and YLW. Data acquisition: YLW, FW, GLC and YZ. Data analysis and interpretation: GJD, XCY, CPX, WC and YLW. Manuscript preparation: GJD, YLW and FW. Manuscript review: GJD, XCY and WC. Corresponding author: GJD, XCY. All authors read and approved the final manuscript.

\section{Ethics approval and consent to participate}

The study was approved by the Ethics Committee of Southwest Hospital, Third Military Medical University (Army Medical University), Chongqing, China (No. KY201818). Written informed consent was obtained from the patients for the storage of samples and data, follow-up contact, and further use of samples and data for research purposes.

\section{Consent for publication}

Not applicable.

\section{Competing interests}

The authors declare that they have no competing interests.

\section{Publisher's Note}

Springer Nature remains neutral with regard to jurisdictional claims in published maps and institutional affiliations.

Received: 22 October 2018 Accepted: 2 January 2019

Published online: 15 January 2019

\section{References}

1. Saygin C, Uzunaslan D, Ozguroglu M, Senocak M, Tuzuner N. Dendritic cell sarcoma: a pooled analysis including 462 cases with presentation of our case series. Crit Rev Oncol Hematol. 2013;88:253-71.

2. Duan GJ, Wu F, Zhu J, et al. Extranodal follicular dendritic cell sarcoma of the pharyngeal region: a potential diagnostic pitfall, with literature review. Am J Clin Pathol. 2010;133:49-58

3. Perez-Ordonez B, Erlandson RA, Rosai J. Follicular dendritic cell tumor: report of 13 additional cases of a distinctive entity. Am J Surg Pathol. 1996;20:944-55.

4. Chan JK, Fletcher CD, Nayler SJ, Cooper K. Follicular dendritic cell sarcoma. Clinicopathologic analysis of 17 cases suggesting a malignant potential higher than currently recognized. Cancer. 1997;79:294-313.

5. Fassina A, Marino F, Poletti A, Rea F, Pennelli N, Ninfo V. Follicular dendritic cell tumor of the mediastinum. Ann Diagn Pathol. 2001;5:361-7.

6. Pileri SA, Grogan $T M$, Harris NL, et al. Tumours of histiocytes and accessory dendritic cells: an immunohistochemical approach to classification from the international lymphoma study group based on 61 cases. Histopathology. 2002:41:1-29.

7. Ceresoli GL, Zucchinelli P, Ponzoni M, Gregorc V, Bencardino K, Paties CT. Mediastinal follicular dendritic cell sarcoma. Haematologica. 2003;88:ECR04.

8. Kröber SM, Marx A, Aebert H, Dohmen BM, Kaiserling E. Sarcoma of follicular dendritic cells in the dorsal mediastinum. Hum Pathol. 2004;35:259-63.

9. Guettier C, Validire P, Emilie D, et al. Follicular dendritic cell tumor of the mediastinum: expression of fractalkine and SDF-1alpha as mast cell chemoattractants. Virchows Arch. 2006;448:218-22.

10. Jiang L, Admirand JH, Moran C, Ford RJ, Bueso-Ramos CE. Mediastinal follicular dendritic cell sarcoma involving bone marrow: a case report and review of the literature. Ann Diagn Pathol. 2006;10:357-62.

11. Leipsic JA, McAdams HP, Sporn TA. Follicular dendritic cell sarcoma of the mediastinum. AJR Am J Roentgenol. 2007:188:W554-6.

12. Soriano AO, Thompson MA, Admirand JH, et al. Follicular dendritic cell sarcoma: a report of 14 cases and a review of the literature. Am J Hematol. 2007:82:725-8

13. Meijs M, Mekkes J, van Noesel $\mathrm{C}$, et al. Paraneoplastic pemphigus associated with follicular dendritic cell sarcoma without Castleman's disease; treatment with rituximab. Int I Dermatol. 2008;47:632-4.

14. Dakak M, Yücel O, Genc O, Cicek AF, Guler A. Follicular dendritic cell sarcoma of mediastinum (case report). Anatol J Clin Investig. 2009;3:77-9.

15. Hartert M, Ströbel P, Dahm M, Nix W, Marx A, Vahl CF. A follicular dendritic cell sarcoma of the mediastinum with immature $T$ cells and association with myasthenia gravis. Am J Surg Pathol. 2010:34:742-5.

16. Li L, Shi YH, Guo ZJ, et al. Clinicopathological features and prognosis assessment of extranodal follicular dendritic cell sarcoma. World J Gastroenterol. 2010;16:2504-19.
17. Westphal FL, Lima LC, Santana LC, Netto JC, Amaral VC, Silva Mdos S. Castleman's disease associated with follicular dendritic cell sarcoma and myasthenia gravis. J Bras Pneumol. 2010;36:819-23.

18. Long-Hua Q, Qin X, Ya-Jia G, Jian W, Xiao-Yuan F. Imaging findings of follicular dendritic cell sarcoma: report of four cases. Korean J Radiol. 2011; 12:122-8.

19. Subesinghe M, Smith JT, Chowdhury FU. F-18 FDG PET/CT imaging of follicular dendritic cell sarcoma of the mediastinum. Clin Nucl Med. 2012;37:204-5.

20. Sanna S, Monteverde M, Taurchini M, Grossi W, Dubini A, Dell'Amore D. Multimodal treatment of mediastinal follicular dendritic cell sarcoma: a case report successfully treated. World J Surg Med Radiat Oncol. 2013;2:1-5.

21. Kim H, Park CM, Jeon YK, Paeng JC, Goo JM, Lee HJ. Follicular dendritic cell sarcoma of the mediastinum: CT and 18F-fluoro-2-deoxyglucose PET findings. Thorac Cancer. 2013:4:203-6.

22. Lee BE, Korst RJ, Taskin M. Right pneumonectomy for resection of a posterior mediastinal follicular dendritic cell sarcoma arising from Castleman's disease. Ann Thorac Surg. 2014;97:e101-3.

23. Bushan K. Follicular dendritic cell sarcoma mediastinum - a case report. Indian J Surg Oncol. 2014;5:290-2.

24. Chow SC, Yeung EC, Ng CS, Wong RH, Fai To K, Wan IY. Mediastinal follicular dendritic cell sarcoma with paraneoplastic pemphigus. Asian Cardiovasc Thorac Ann. 2015:23:732-4.

25. Spatola C, Migliore M, Emanuele Liardo RL, et al. Follicular dendritic cell sarcoma of mediastinum: a key role of radiotherapy in a multidisciplinary approach. Future Oncol. 2015;11:57-61.

26. Prakasan AM, Prabhu AJ, Velarasan K, Backianathan S, Ram TS. Paraneoplastic pemphigus associated with follicular dendritic cell tumor in the mediastinum. Case Rep Dermatol Med. 2016;2:1-4

27. Hu J, Dong D, Jiang Z, Hu H. Clinicopathological characteristics of mediastinal follicular dendritic cell sarcoma: report of three cases. J Cardiothorac Surg. 2016;11:56.

28. Viola P, Vroobel KM, Devaraj A, et al. Follicular dendritic cell tumour/ sarcoma: a commonly misdiagnosed tumour in the thorax. Histopathology. 2016;69:752-61.

29. Miyoshi R, Sonobe M, Miyamoto E, Date H. Completely resected follicular dendritic cell sarcoma of the posterior mediastinum: report of a case. Surg Case Rep. 2016;2:28.

30. Cingam SR, Al Shaarani M, Takalkar A, Peddi P. Follicular dendritic sarcoma masquerading as fibrosing mediastinitis. BMJ Case Rep. 2017. https://doi. org/10.1136/bcr-2016-218889.

31. Purkait S, Mallick S, Joshi PP, et al. Retroperitoneal and mediastinal follicular dendritic cell sarcoma: report of 3 cases with review of literature. Hematol Oncol. 2017;35:374-9.

32. Lorenzi L, Döring C, Rausch T, et al. Identification of novel follicular dendritic cell sarcoma markers, FDCSP and SRGN, by whole transcriptome sequencing. Oncotarget. 2017:8:16463-72.

33. Cheuk W, Chan JK, Shek TW, et al. Inflammatory pseudotumor-like follicular dendritic cell tumor: a distinctive low-grade malignant intra-abdominal neoplasm with consistent Epstein-Barr virus association. Am J Surg Pathol. 2001;25:721-31.

34. Duan GJ, Wu YL, Sun H, Lang L, Chen ZW, Yan XC. Primary follicular dendritic cell sarcoma of the urinary bladder: the first case report and potential diagnostic pitfalls. Diagn Pathol. 2017;12:35.

35. Facchetti F, Pileri SA, Lorenzi L, et al. Histiocytic and dendritic cell neoplasms: what have we learnt by studying 67 cases. Virchows Arch. 2017:471:467-89.

36. Pang J, Mydlarz WK, Gooi Z, et al. Follicular dendritic cell sarcoma of the head and neck: case report, literature review, and pooled analysis of 97 cases. Head Neck. 2016;38:E2241-9.

37. Jain P, Prieto VG, Manning JT, Fowler N, Medeiros $L$, Kanagal-Shamanna R Synchronous presentation of intra-nodal follicular dendritic cell sarcoma and Castleman disease. Am J Hematol. 2017:92:478-9.

38. Chan AC, Chan KW, Chan JK, Au WY, Ho WK, Ng WM. Development of follicular dendritic cell sarcoma in hyaline-vascular Castleman's disease of the nasopharynx: tracing its evolution by sequential biopsies. Histopathology. 2001;38:510-8.

39. Chen Y, Shi H, Li H, Zhen T, Han A. Clinicopathological features of inflammatory pseudotumour-like follicular dendritic cell tumour of the abdomen. Histopathology. 2016;68:858-65.

40. Go H, Jeon YK, Huh J, et al. Frequent detection of BRAF (V600E) mutations in histiocytic and dendritic cell neoplasms. Histopathology. 2014;65:261-72. 
41. Griffin GK, Sholl LM, Lindeman NI, Fletcher CD, Hornick JL. Targeted genomic sequencing of follicular dendritic cell sarcoma reveals recurrent alterations in NF-KB regulatory genes. Mod Pathol. 2016;29:67-74.

42. Hartmann $\mathrm{S}$, Doring $\mathrm{C}$, Agostinelli $\mathrm{C}$, et al. miRNA expression profiling divides follicular dendritic cell sarcomas into two groups, related to fibroblasts and myopericytomas or Castleman's disease. Eur J Cancer. 2016;64:159-66.

43. Laginestra MA, Tripodo C, Agostinelli C, et al. Distinctive histogenesis and immunological microenvironment based on transcriptional profiles of follicular dendritic cell sarcomas. Mol Cancer Res. 2017;15:541-2.

Ready to submit your research? Choose BMC and benefit from:

- fast, convenient online submission

- thorough peer review by experienced researchers in your field

- rapid publication on acceptance

- support for research data, including large and complex data types

- gold Open Access which fosters wider collaboration and increased citations

- maximum visibility for your research: over $100 \mathrm{M}$ website views per year

At $B M C$, research is always in progress.

Learn more biomedcentral.com/submissions 